\title{
Социально-психологическая интерпретация личности преподавателя как фактор оценки студентами учебной онлайн-лекции
}

\author{
В.Н. Панферов, С.А. Безгодова, С.В. Васильева, А.В. Микляева \\ Российский государственный педагогический университет им. А. И. Герцена \\ v-panferov@mai I.ru, s.a.bezgodova@gmai I.com,vivatsv@mai I.ru, \\ a.mi klyaeva@gmai I.com
}

\section{Аннотация}

Статья содержит результаты эмпирического исследования социальнопсихологической интерпретации личности преподавателя студентами во время просмотра видео-лекции.

Был описан эталонный образ преподавателя, характеризующийся коммуникативным, нравственным, регуляторным и рефлексивным потенциалом. Проведено сравнение характеристик эталонного преподавателя с преподавателем, лекция которого вызвала наибольший интерес и позитивную эмоциональную реакцию.

Показано, что наибольший вклад в формирование студенческих оценок интереса к онлайн-лекции и готовности к ее самостоятельному просмотру вносит атрибуция преподавателю качеств, характеризующих коммуникативную сферу его личности.

Ключевые слова: онлайн обучение, студенты, социальная перцепция, социальнопсихологическая интерпретация личности, эталонный образ преподавателя

Библиографическая ссылка: Панферов В.Н., Безгодова С.А., Васильева С.В., Микляева А.В. Социально-психологическая интерпретация личности преподавателя как фактор оценки студентами учебной онлайн-лекции // Информационное общество: образование, наука, культура и технологии будущего. Выпуск 3 (Труды XXII Международной объединенной научной конференции «Интернет и современное общество», IMS-2019, Санкт-Петербург, 19 - 22 июня 2019 г. Сборник научных трудов). - СПб: Университет ИТМО, 2019. С. $202-210$. DOI: $10.17586 / 2587-8557-2019-3-202-210$

\section{Введение}

Популярность дистанционных технологий в сфере высшего образования сегодня стремительно растет. Причинами востребованности студентами дистанционного формата обучения является возможность гибко строить график учебного процесса, обучаться у ведущих специалистов, проживающих в других городах и странах, относительно низкой стоимостью онлайн-обучения (в сравнении с очной формой) и т.д.

Однако при очевидных достоинствах онлайн-обучение таит в себе и определенные трудности, не свойственные очному формату образования. Так, согласно результатам исследования S. Sun, студенты, выбравшие онлайн-образование, сталкиваются с необходимостью самостоятельно обеспечивать регулярность занятий, что может негативно сказаться на их намерениях пройти программу обучения полностью, испытывают дефицит контактов со студентами, обучающимися на той же образовательной программе, в силу чего не могут использовать в полной мере обучающие ресурсы совместной работы, а также не всегда имеют возможность получить своевременную обратную связь от преподавателя [1]. Если на первых этапах развития технологий 
дистанционного образования, пока они еще не имели столь существенного распространения, исследователи не отмечали существенных различий в эффективности традиционного и онлайн-образования [2,3], то сегодня констатируется, что его эффективность может существенно варьироваться [4]. По данным целого ряда авторов, в современных условиях, когда спектр обучающих видеоматериалов достаточно широк, и студент почти всегда имеет возможность выбора из нескольких вариантов видеолекций, посвященных одной и той же теме, на первый план выходит готовность студента к использованию конкретного видеоматериала в учебных целях $[5,6]$.

Согласно V.A. Thurmond и др., [7], оценка студентами любого дистанционного образовательного продукта является результирующей характеристик их взаимодействия в системах «студент - интерфейс», «студент - содержание учебной дисциплины», «студент - студент» и «студент - преподаватель». Анализируя литературу, посвященную онлайнобразованию, можно отметить, что первые три системы, выделенные V.A. Thurmond, изучаются сегодня довольно активно. Так, в контексте проблемы эффективности онлайнобразования изучаются технические $[8,9]$ и дидактические [10] характеристики видеолекций. В зарубежной психологии набирает популярность изучение закономерностей взаимодействия между студентами-слушателями онлайн-курсов. Однако четвертая система зачастую остается вне фокуса исследовательского внимания Отечественными и зарубежными исследователями констатируется, что коммуникация, опосредованная техническими средствами, имеет отличия, которые необходимо учитывать при подготовке видеолекций $[11,12]$, однако экспериментальные данные, которые раскрывали бы специфику педагогической коммуникации в условиях онлайн-образования, носят весьма фрагментарный характер, что и определило цели и задачи нашего исследования.

Поскольку педагогическая коммуникация представляет собой сложнейший многоплановый процесс, мы сосредоточили внимание только лишь на одном из его аспектов, выбрав в качестве предмета исследования особенности социальнопсихологической интерпретации личности преподавателя в условиях онлайн-лекции. С нашей точки зрения, социально-психологическая интерпретация личности преподавателя, понимаемая нами как процесс формирования суждений студентов о преподавателе, возникающих на основе восприятия и семантизации его внешности и поведения [13], является одним из ключевых факторов эффективности педагогической коммуникации и может в этой связи рассматриваться в качестве одного из предикторов оценки эффективности онлайн-лекции студентами.

Цель нашего исследования заключалась в изучении взаимосвязей между характеристиками социально-психологической интерпретации личности преподавателя студентами и их оценками учебной онлайн-лекции. В исследовании использовались два оценочных критерия: критерий интереса и критерий готовности к самостоятельному просмотру подобного онлайн-материала. Соответственно, были сформулированы два исследовательских вопроса. Первый вопрос касался специфики содержания социальнопсихологической интерпретации личности преподавателя в условиях онлайнкоммуникации, который конкретизировался нами в задачу сравнения образа преподавателя, возникающего в ходе просмотра онлайн-лекции, и эталонного образа преподавателя. Второй исследовательский вопрос был связан с анализом взаимосвязей между качествами, атрибутируемыми преподавателю в ходе просмотра онлайн-лекции, и оценками представленного им учебного материала по параметрам интереса и готовности к самостоятельному просмотру.

\section{Материалы и методы}

Исследование проводилось в два этапа. На первом этапе выявлялся эталонный образ преподавателя. Для этого респондентам предлагалось охарактеризовать «идеального 
преподавателя», используя шкалы «Личностного дифференциала» [14]. Опрос был проведен в онлайн-формате. В данном этапе исследования приняли участие 303 студента высших учебных заведений в возрасте 17-28 лет.

На втором этапе исследования респондентам было предложено охарактеризовать личность незнакомого им ранее преподавателя на основе просмотра фрагмента видеолекции. На этом этапе исследования приняли участие 35 студентов в возрасте 18-22 года, обучающихся по правлениям «Психология» и «Психолого-педагогическое образование». Студенты психологических направлений подготовки были выбраны в качестве испытуемых не случайно, поскольку в связи со спецификой профессиональной подготовки являются более подготовленными к оценке других людей и могут дать более развернутые и информативные ответы, касающиеся социально-психологической интерпретации личности воспринимаемого, что для первичного эксперимента является значимым фактом в возможности получения большего объема эмпирических данных. Студентам были предложены для оценки фрагменты четырех видеолекций по теме «Психология внимания», выложенные в сети Интернет в свободном доступе. Стимульный материал был уравнен по тематике, профессиональному статусу преподавателя (ученая степень не ниже кандидата психологических наук), сбалансирован по полу и возрасту преподавателей, а также параметрам организации съемки и использования дополнительных иллюстративных материалов (см. табл. 1, нумерация фрагментов произвольна и не отражает порядок их предъявления студентам).

Таблица 1. Характеристика видеофрагментов

\begin{tabular}{|c|c|c|c|c|}
\hline \multirow{2}{*}{$\begin{array}{c}\text { Параметры } \\
\text { сравнения }\end{array}$} & \multicolumn{4}{|c|}{ № фрагмента } \\
\hline & 1 & 2 & 3 & 4 \\
\hline Тема лекции & $\begin{array}{l}\text { Психология } \\
\text { внимания }\end{array}$ & $\begin{array}{l}\text { Психология } \\
\text { внимания }\end{array}$ & $\begin{array}{l}\text { Психология } \\
\text { внимания }\end{array}$ & $\begin{array}{l}\text { Психология } \\
\text { внимания }\end{array}$ \\
\hline $\begin{array}{l}\text { Возраст } \\
\text { преподавателя }\end{array}$ & 40-50 лет & 40-50 лет & 40-50 лет & 40-50 лет \\
\hline $\begin{array}{l}\text { Пол } \\
\text { преподавателя }\end{array}$ & Мужской & Женский & Мужской & Мужской \\
\hline Ученая степень & $\begin{array}{l}\text { Кандидат } \\
\text { психологических } \\
\text { наук }\end{array}$ & $\begin{array}{l}\text { Кандидат } \\
\text { психологических } \\
\text { наук }\end{array}$ & $\begin{array}{l}\text { Кандидат } \\
\text { психологических } \\
\text { наук }\end{array}$ & $\begin{array}{l}\text { Кандидат } \\
\text { психологических } \\
\text { наук }\end{array}$ \\
\hline $\begin{array}{l}\text { Присутствие } \\
\text { слушателей } \\
\text { время съемки }\end{array}$ & Да & Нет & Нет & Да \\
\hline $\begin{array}{l}\text { Использование } \\
\text { иллюстративных } \\
\text { материалов }\end{array}$ & Нет & Нет & Да & Да \\
\hline
\end{tabular}

После завершения просмотра каждого видеофрагмента студентам предлагалось охарактеризовать личность преподавателя, используя шкалы «Личностного дифференциала», а также дать оценку видеофрагмента по нескольким параметрам, в том числе по параметрам «интерес» и «готовность смотреть подобные видеолекции самостоятельно, вне учебных занятий» (с использованием оценочной 7-балльной шкалы).

Для обработки результатов исследования использовался пакет прикладных программ Statistica 10.0, с помощью которого осуществлялись критериальный (критерий МаннаУитни $Z$, критерий Краскела-Уоллиса $H$ ), корреляционный (коэффициент корреляции Спирмена $r_{s}$ ) и регрессионный анализ. 


\section{Результаты исследования}

Анализ оценок видеофрагментов показал, что оценки, сформулированные студентами по разным параметрам, тесно связаны друг с другом $\left(\mathrm{r}_{\mathrm{s}}=0,89, \mathrm{p}<0,001\right)$. В качестве видеофрагментов для анализа качеств, атрибутируемых личности преподавателя в условиях привлекательной и непривлекательной видеолекции, на основании анализа усредненных оценок были выбраны фрагмент 1 и 4 (см. рис. 1).

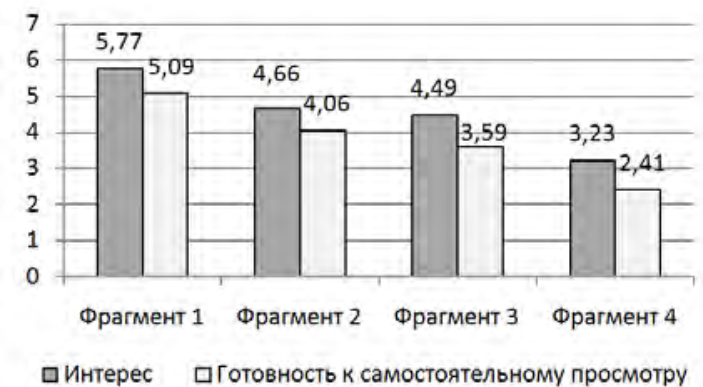

Рис. 1. Усредненные оценки видеофрагментов

На основании полученных данных были построены личностные профили «идеального преподавателя», и также профили личностных качеств, атрибутируемых преподавателям авторам привлекательной и непривлекательной видеолекции (см. рис. 2). Результаты показывают, что преподавателю, представившему привлекательную лекцию, студенты приписывают ряд личностных качеств, входящих в профиль «идеального преподавателя» (разговорчивость, доброта, независимость, активность, энергичность), в то время как профиль качеств, атрибутируемых преподавателю-автору непривлекательной лекции, отличается от профиля «идеального преподавателя» значительно более существенно.

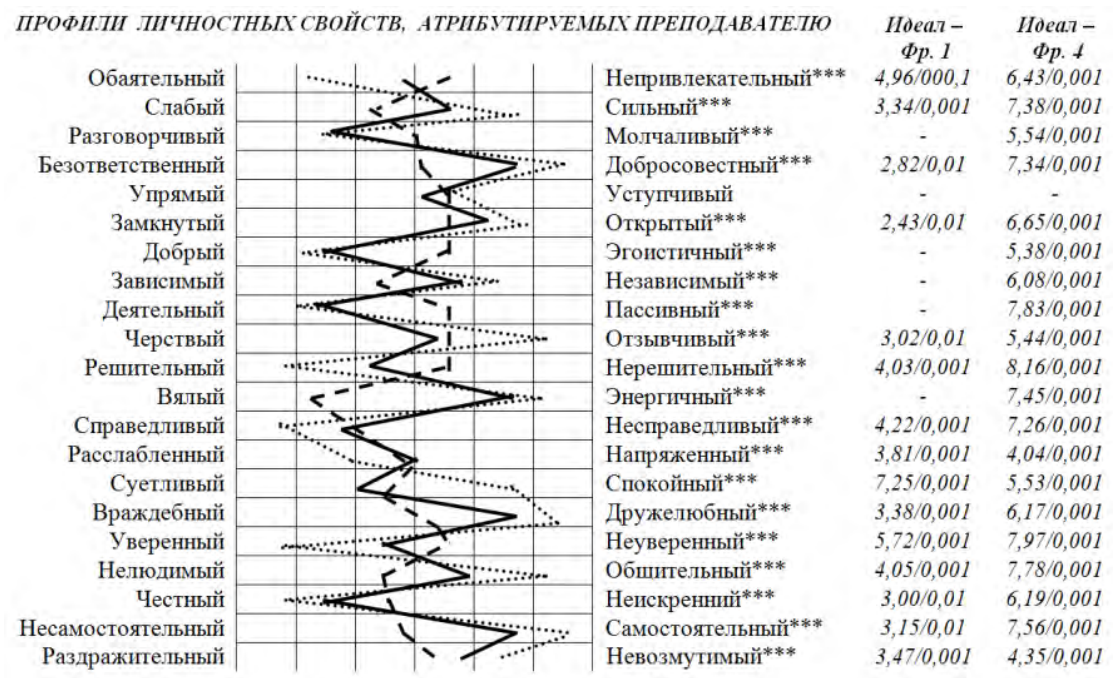

......и идеальный преподаватель; — фрагмент 1; - - фрагмент 4

Рис. 2. Профили качеств, атрибутируемых преподавателю

*** - профили имеют достоверные различия, критерий $\mathrm{H}, \mathrm{p}<0,001$

Идеал - Фр. 1, Идеал - Фр. 2 - различия между профилем качеств, атрибутируемых идеальному преподавателю и преподавателям, представленным во фрагментах 1 и 4 соответственно $(\mathrm{Z} / \mathrm{p}<)$ 
Корреляционный анализ показал, что, несмотря на отмеченное выше сходство оценок фрагментов видеолекций по параметрам «интерес» и «готовность к самостоятельному просмотру», корреляционные связи этих оценок с оценками выраженности качеств личности, атрибутируемых преподавателю, различаются. Так, оценка «интереса» оказалась положительно связанной с атрибуцией преподавателю качеств обаятельности $\left(r_{s}=0,58\right)$, активности $\left(r_{s}=0,50\right)$, уверенности $\left(r_{s}=0,58\right)$, и отзывчивости $\left(r_{s}=0,52\right)$, в то время как оценка «готовности к самостоятельному просмотру» - общительности $\left(r_{s}=0,55\right)$, открытости $\left(r_{s}=0,51\right)$ и независимости $\left(r_{s}=0,50\right)$.

Регрессионный анализ продемонстрировал различия в предикторах оценок «интереса» и «готовности к самостоятельному просмотру»: в первом случае в их число вошли обаятельность, добросовестность, отзывчивость и общительность, во втором независимость и общительность (см. табл.2).

Таблица 2. Результаты регрессионного анализа

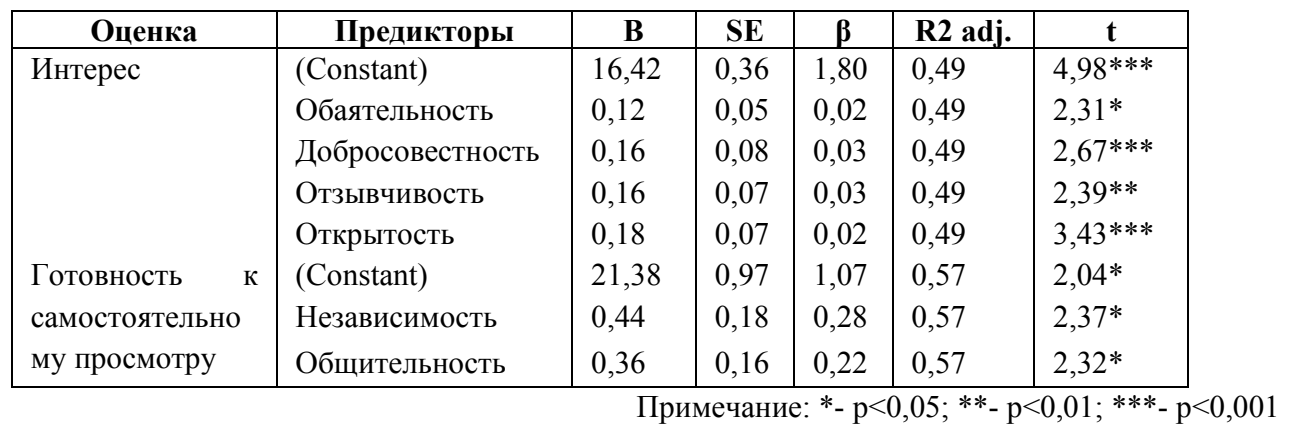

\section{Обсуждение}

Согласно полученным нами результатам, образ идеального преподавателя, рассматриваемый в нашем исследовании в качестве эталонного, представлен в сознании студентов преимущественно теми качествами, которые характеризуют коммуникативный, нравственный, регуляторный и рефлексивный потенциал личности. К числу наиболее ярко выраженных качеств в структуре этого образа относятся общительность, дружелюбие и отзывчивость (коммуникативный потенциал), добросовестность, справедливость и честность (нравственный потенциал), энергичность, решительность и самостоятельность (регуляторный потенциал), уверенность (рефлексивный потенциал). В целом наши данные подтверждают представленные в литературе сведения о том, что студенческим представлениям об идеальном преподавателе свойственна целостность, интегрированность в их содержание характеристик, в которых находят отражение разные стороны психического потенциала $[15,16]$.

В сравнении с эталонным образом, в числе качеств, атрибутируемых личности преподавателя, чья лекция была оценена студентами как привлекательная, можно отметить относительно меньшие оценки нравственных и рефлексивных качеств личности при сохранении значения качеств регуляторного и коммуникативного потенциала. Особенно ярко эта тенденция проявляется при анализе значимых различий, выявленных между профилями личностных качеств, приписываемых «идеальному преподавателю» и преподавателю, представившему привлекательную лекцию: различий между этими профилями не обнаружено именно по показателям регуляторных (независимость, упрямство, энергичность) и коммуникативных (разговорчивость, уступчивость, эгоистичность) свойств личности. Эти данные согласуются с нашими предыдущими результатами, согласно которым, в частности, атрибуция преподавателю тех или иных нравственных качеств в процессе знакомства с онлайн-лекцией не связана с оценками 
привлекательности - непривлекательности этой лекции, наиболее существенные связи с которыми демонстрирует атрибуция преподавателю коммуникативных и регуляторных свойств [17]. Обращает на себя внимание тот факт, что преподавателю, чья лекция была оценена студентами как наименее привлекательная, студенты чаще всего приписывали среднюю степень выраженности предложенных в «Личностном дифференциале» характеристик, что позволяет в целом охарактеризовать образ этого преподавателя как «отсутствие индивидуальности».

Анализируя результаты корреляционного и регрессионного анализа, можно отметить, что в оценки онлайн-лекций, предложенные студентами, связаны, в первую очередь, с атрибуцией преподавателю коммуникативных свойств, в то время как связи с регуляторными и нравственными свойствами носят единичный характер, а качества рефлексивного потенциала не представлены в структуре этих взаимосвязей вообще. Регрессионный анализ позволяет предполагать, что универсальным предиктором студенческих оценок онлайн-лекции является атрибуция преподавателю таких личностных качеств, которые приближены к коммуникативной составляющей идентификационного эталона. На наш взгляд, этот факт может интерпретироваться как выражение значимости для студентов контакта с преподавателем в условиях опосредованной педагогической коммуникации и, учитывая специфичность средств коммуникации в онлайн-пространстве [18], демонстрирует важность поиска тех форм поведения преподавателя, которые интерпретировались бы студентами как готовность к контакту с ними, и, следовательно, способствовали бы повышению их оценок онлайнлекций в аспектах интереса и готовности к самостоятельному просмотру.

\section{Выводы}

В соответствии со сформулированными нами исследовательскими вопросами мы можем констатировать, что социально-психологическая интерпретация личности преподавателя студентами в условиях видеолекции предполагает, прежде всего, атрибуцию преподавателю свойств личности, характеризующих его коммуникативный и регуляторный потенциал. При этом наибольший вклад в формирование студенческих оценок интереса к онлайн-лекции и готовности к ее самостоятельному просмотру вносит атрибуция преподавателю качеств, характеризующих коммуникативную сферу его личности. Эти результаты необходимо учитывать в процессе подготовки видео-контента для учебных онлайн-курсов, что предполагает необходимость более детального изучения особенностей внешности и поведения преподавателя, которые интерпретируются студентами как готовность к коммуникации и тем самым способствуют повышению эффективности онлайн-лекций. Вместе с тем, для верификации полученных результатов и проверки их релевантности для генеральной совокупности студентов необходимо расширение выборки студентами непсихологических профилей подготовки.

Работа выполнена при поддержке Российского фонда фундаментальных исследований, грант № 19-013-00412.

\section{Литература}

[1] Sun S.Y.H. Learner Perspectives on Fully Online Language Learning // Distance Education. 2014. Vol. 35, №. 1. P. 18-42. doi:10.1080/01587919.2014.891428.

[2] Russell T. L. The No Significant Difference Phenomenon, Office of Instructional Telecommunications, North Carolina State University, Chapel Hill, North Carolina, 1999.

[3] Allen M., Mabry E., Mattrey M., Bourhuis J., Titsworth S. and Burrell N. Evaluating the effectiveness of distance learning: A comparison using meta-analysis. Journal of Communication. 2004. Vol. 5, №3. P. 402-420. 
[4] Chapin L.A. Australian university students' access to web-based lecture recordings and the relationship with lecture attendance and academic performance //Australasian Journal of Educational Technology. 2018. Vol.34, №5. P.1-12.

[5] Spears R. \& Lea M. Breaching or building social boundaries? SIDE-effects of computermediated communication. // Communication Research. 1998. №2. P. 689-715.

[6] Postmes T., Spears R., \& Lea M. The formation of group norms in computer-mediated communication. // Human Communication Research. 2000. №26. P.341-371.

[7] Thurmond V.A., Wambach K., Connors H.R., Frey B.B. Evaluation of student satisfaction: Determining the impact of a Web-based environment by controlling for student characteristics // The American Journal of Distance Education. 2002. Vol. 16, №3. P. 169189.

[8] Никишина В.Б., Запесоцкая И.В., Кузнецова А.А. Технология создания видеолекций: мифы и реальность // Современные проблемы науки и образования. 2017 № 4. С. 139.

[9] Давлеткиреева Л.З., Ролина К.М. Использование видеоконтента для повышения эффективности процесса обучения и индивидуализации: виды, технологии, программы // Дистанционные образовательные технологии. Материалы II Всероссийской научнопрактической интернет-конференции. Симферополь: Ариал, 2017. С. 120-130.

[10]Шалыгина И.В., Шабалин Ю.Е. Дидактика учебных видеолекций // Информация и образование: границы коммуникаций. 2012. Том 4. №12. С.223-230.

[11]Cole A.W.; Allen M.; Anderson C.; Bunton T.; Cherney M. R.; Draeger Jr. R.; Featherston M.; Fisher V. C.; Motel L.; Nicolini K. M. \& Peck B. Student predisposition to instructor feedback and perceptions of teaching presence predict motivation toward online courses. Online Learning. 2017. Vol.21, №4, P.245-262.

[12]Орлова А.В. Особенности социальной перцепции лица человека, предъявляемого на экране монитора: автореферат дис. ... канд. пс. н. СПб., 2009. 24 с.

[13]Панферов В.Н. Интегральный синтез психологии человека в науке, в образовании, в социальном взаимодействии. СПб.: Изд-во РГПУ им. А. И. Герцена, 2015. 761 с.

[14]Бажин Е.Ф., Эткинд А.М. Личностный дифференциал. Методические рекомендации. Л.: Изд-во ЛНИПНИ им. В.М. Бехтерева, 1983. 12 с.

[15]Есипова А.А., Сатывалдиева Б. Образ современного педагога высшей школы // Педагогика высшей школы. 2015. №3.1. С. 75-78.

[16]Пучков А.А. Идеальный образ преподавателя: социологический опрос // Высшее образование в России. 2012. № 6. С. 130-133.

[17]Панферов В.Н., Безгодова С.А., Васильева С.В., Микляева А.В. Социальнопсихологическая интерпретация личности преподавателя в условиях видеолекции // Азимут научных исследований: педагогика и психология. 2018. Том 7. № 3 (24). С. 365-368.

[18] Cole A. W.; Allen M.; Anderson C.; Bunton T.; Cherney M. R.; Draeger Jr., R.; Featherston M.; Fisher V. C.; Motel L.; Nicolini, K. M. \& Peck B. Student predisposition to instructor feedback and perceptions of teaching presence predict motivation toward online courses. Online Learning. Vol. 21, №4. P.245-262.

\title{
Socio-psychological Interpretation of the Teacher's Personality as a Factor of Students ' Evaluation of Educational Online Lectures
}

\author{
V.N. Panferov, S.A. Bezgodova, S.V. Vasilyeva, A.V. Miklyaeva
}

Herzen State Pedagogical University of Russia

The paper contains the results of an empirical study of the socio-psychological interpretation of the teacher's personality by students while watching a video lecture. The reference image of the 
teacher characterized by communicative, moral, regulatory and reflexive potential was described. A comparison of the characteristics of the reference teacher with the teacher, whose lecture aroused the greatest interest and positive emotional reaction.

It is shown that the greatest contribution to the formation of student assessments of interest in online lectures and readiness for its independent viewing is made by attribution to the teacher of the qualities characterizing the communicative sphere of his personality.

The necessity of a more detailed study of the features of the appearance and behavior of the teacher, which are interpreted by students as a willingness to communicate and thus contribute to the effectiveness of online lectures.

Keywords: on-line training; students; social perception; socio-psychological interpretation of personality; the standard image of the teacher

Reference for citation: Panferov V.N., Bezgodova S.A., Vasilyeva S.V., Miklyaeva A.V. Sociopsychological Interpretation of the Teacher's Personality as a Factor of Students ' Evaluation of Educational Online Lectures // Information Society: Education, Science, Culture and Technologies of the Future. Vol. 3 (Proceedings of the XXII International Joint Scientific Conference «Internet and Modern Society», IMS-2019, St. Petersburg, June 19-22, 2019). St. Petersburg: ITMO University, 2019. P. 202 - 210. DOI: 10.17586/2587-8557-2019-3-202-210

\section{Reference}

[1] Sun S.Y.H. Learner Perspectives on Fully Online Language Learning // Distance Education. 2014. Vol. 35, №. 1. P. 18-42. doi:10.1080/01587919.2014.891428.

[2] Russell T. L. The No Significant Difference Phenomenon, Office of Instructional Telecommunications, North Carolina State University, Chapel Hill, North Carolina, 1999.

[3] Allen M., Mabry E., Mattrey M., Bourhuis J., Titsworth S. and Burrell N. Evaluating the effectiveness of distance learning: A comparison using meta-analysis. Journal of Communication. 2004. Vol. 5, №3. P. 402-420.

[4] Chapin L.A. Australian university students' access to web-based lecture recordings and the relationship with lecture attendance and academic performance //Australasian Journal of Educational Technology. 2018. Vol.34, №5. P.1-12.

[5] Spears R. \& Lea M. Breaching or building social boundaries? SIDE-effects of computermediated communication. // Communication Research. 1998. №2. P. 689-715.

[6] Postmes T., Spears R., \& Lea M. The formation of group norms in computer-mediated communication. // Human Communication Research. 2000. №26. P.341-371.

[7] Thurmond V.A., Wambach K., Connors H.R., Frey B.B. Evaluation of student satisfaction: Determining the impact of a Web-based environment by controlling for student characteristics // The American Journal of Distance Education. 2002. Vol. 16, №3. P. 169189.

[8] Nikishina V.B., Zapesockaya I.V., Kuznecova A.A. Tekhnologiya sozdaniya videolekcij: mify i real'nost' // Sovremennye problemy nauki i obrazovaniya. 2017 № 4. S. 139.

[9] Davletkireeva L.Z., Rolina K.M. Ispol'zovanie videokontenta dlya povysheniya ehffektivnosti processa obucheniya i individualizacii: vidy, tekhnologii, programmy // Distancionnye obrazovatel'nye tekhnologii. Materialy II Vserossijskoj nauchno-prakticheskoj internet-konferencii. Simferopol': Arial, 2017. S. 120-130.

[10] Shalygina I.V., SHabalin YU.E. Didaktika uchebnyh videolekcij // Informaciya i obrazovanie: granicy kommunikacij. 2012. Tom 4. №12. S.223-230.

[11]Cole A.W.; Allen M.; Anderson C.; Bunton T.; Cherney M. R.; Draeger Jr. R.; Featherston M.; Fisher V. C.; Motel L.; Nicolini K. M. \& Peck B. Student predisposition to instructor feedback and perceptions of teaching presence predict motivation toward online courses. Online Learning. 2017. Vol.21, №4, P.245-262. 
[12] Orlova A.V. Osobennosti social'noj percepcii lica cheloveka, pred"yavlyaemogo na ehkrane monitora : avtoreferat dis. ... kand. ps. n. SPb., 2009. 24 s.

[13] Panferov V.N. Integral'nyj sintez psihologii cheloveka v nauke, v obrazovanii, v social'nom vzaimodejstvii. SPb.: Izd-vo RGPU im. A. I. Gercena, 2015. $761 \mathrm{s.}$

[14]Bazhin E.F., EHtkind A.M. Lichnostnyj differencial. Metodicheskie rekomendacii. L.: Izdvo LNIPNI im. V.M. Bekhtereva, 1983. $12 \mathrm{~s}$.

[15] Esipova A.A., Satyvaldieva B. Obraz sovremennogo pedagoga vysshej shkoly // Pedagogika vysshej shkoly. 2015. №3.1. S. 75-78.

[16] Puchkov A.A. Ideal'nyj obraz prepodavatelya: sociologicheskij opros // Vysshee obrazovanie v Rossii. 2012. № 6. S. 130-133.

[17]Panferov V.N., Bezgodova S.A., Vasil'eva S.V., Miklyaeva A.V. Social'nopsihologicheskaya interpretaciya lichnosti prepodavatelya v usloviyah videolekcii // Azimut nauchnyh issledovanij: pedagogika i psihologiya. 2018. Tom 7. № 3 (24). S. 365-368.

[18] Cole A. W.; Allen M.; Anderson C.; Bunton T.; Cherney M. R.; Draeger Jr., R.; Featherston M.; Fisher V. C.; Motel L.; Nicolini, K. M. \& Peck B. Student predisposition to instructor feedback and perceptions of teaching presence predict motivation toward online courses. Online Learning. Vol. 21, №4. P.245-262. 